\title{
I Will Put My Law in Their Minds: Social Control and Cheating Behavior Among Catholics and Protestants
}

\section{ALAIN QUIAMZADE}

Faculté de Psychologie et des Sciences de l'Education University of Geneva

Distance Learning University, Sierre, Switzerland

JAVIERA BURGOS LABORDE

Departamento de Estadísticas e Información en Salud Ministry of Health of Chile

LUIGI GUISO

Einaudi Institute of Economics and Finance

\author{
NiCOLAS SOMMET \\ Faculté des Sciences Sociales et Politiques \\ University of Lausanne
}

JEAN-PAul L'Huillier

Einaudi Institute of Economics and Finance

\begin{abstract}
Catholics and Protestants differ in terms of social autonomy versus heteronomy. We propose that the regulation of behavior in accordance with social norms depends on the social control exercised by an authority for Catholics more than it does for Protestants. Two experiments measured cheating behavior (the transgression of a social norm) as a function of the religious group (Protestant vs. Catholic) and social control (with vs. without). Catholics were found to be more responsive to social control, that is, to cheat less when social control was salient, whereas Protestants' behavior did not depend on this dimension. In Study 2, intrinsic-extrinsic religiousness was found to mediate this difference. Results are discussed in the context of the effects of public policies based on social control.
\end{abstract}

Keywords: religion, Protestants, Catholics, intrinsic-extrinsic religiousness, cheating, social control.

\begin{abstract}
"I will put my law in their minds... No longer will they teach their neighbor,
or say to one another, 'Know the Lord,' because they will all know me,

from the least of them to the greatest," declares the Lord."
\end{abstract}

(Jeremiah 31:33-34 [New International Version])

\section{INTRODUCTION}

The idea of a personal and direct relationship between God and humans was so revolutionary that it triggered not only the so-called Protestant Reformation, but was closely linked to other major European social transformations in the 16th century. Protestantism introduced the idea of a faith based on one's direct affiliation with God, as opposed to Catholicism, in which the Church mediates this connection. These two types of religious structures operate differently

Note: One of the authors is Catholic, one is Protestant, and three are atheists. This research received no specific grant from any funding agency in the public, commercial, or not-for-profit sectors. The raw data are available upon request to the corresponding author and/or to the second author.

Correspondence should be addressed to Alain Quiamzade, Faculté de Psychologie et des Sciences de l'Éducation, University of Geneva, Uni Mail/Bureau 6138, 40 Bd du Pont d'Arve, CH-1205 Genéve, Switzerland. Email: Alain.Quiamzade@unige.ch. 
in people's minds: Protestants tend to be more intrinsically oriented toward religion, whereas Catholics tend to be more extrinsically oriented toward religion. In this article, we argue that Protestants should therefore endorse more self-determined morality-related behavior, whereas Catholics should comply more with the social norm, especially when there is some social control (i.e., the pattern of social pressure aiming to maintain established rules) (Ogburn and Nimkoff 1940).

\section{Intrinsic and Extrinsic Religiousness Among Catholics and Protestants}

Deci and Ryan (1985) defined intrinsic motivation as the tendency to regulate behavior on the basis of integrated values, and extrinsic motivation as the tendency to regulate behavior on the basis of external constraints. Ryan, Rigby, and King (1993) have applied self-determination theory to religion. On the one hand, individuals holding intrinsic religious orientation fully adopt religion as their personal standards and show higher volition. On the other hand, extrinsic religiousness relates to a partial internalization of religion as personal values that are determined by pressure from other people (i.e., introjection). Allport (1950) already proposed a similar distinction between those who are motivated by goals intrinsic to religious practices and beliefs and those who are motivated by goals extrinsic to them. Allport and Ross (1967) developed a scale assessing intrinsic and extrinsic religiousness, with Protestants reporting higher intrinsic orientation and Catholics higher extrinsic orientation (e.g., Cohen and Hill 2007; but see Donahue 1985). Globally, studies suggest that Protestants behave in a more autonomous way and Catholics in a more heteronomous way, thereby being more responsive to authority and control from others.

Such differences in behavior regulation do not concern ex nihilo religious beliefs, but rely on differences in relationship with the authority. In Catholicism, faith is organized through a relationship of normative dependency to the group and its authorities. Socially speaking, it corresponds to a power relationship that implies obedience to the authority (i.e., the Church) and conformity to its norms (Christophe [1982-1983] 2000). By contrast, Protestantism might be viewed as "a free faith," where each believer is able to make his/her own interpretation of biblical histories (within his/her faith tradition). Beyond the religious content itself, Protestantism as introduced by Luther was basically a claim to give freedom of exegesis to each Christian, as well as independency from the Church's social hierarchy. This explains, for example, why Catholicism had more often been in direct conflict with science than Protestantism had (Minois 1991). Historically speaking, the former more strongly asked conclusions drawn from discoveries to conform to the Church's positions, whereas the latter allowed its followers to investigate nature and reality in a more independent way.

These structural differences might explain why Protestants tend to internalize social norms and adhere to them on a more personal basis (intrinsic religiousness), whereas Catholics adhere to norms on the basis of social control, following the authorities that set these norms (see Cohen 2015). Other lines of research are consistent with this idea, with Catholics (but also some fundamentalist Protestants) scoring higher than Protestants on authoritarianism (Adorno et al. 1950; Putney and Middleton 1961), dogmatism (Rokeach 1960, except for Baptists), or valuing more obedience in children (Ellison and Sherkat 1993). It is worth noting that these findings mostly apply to the comparisons between Catholics and Protestants from the so-called mainline denominations (encouraging tolerance for interpersonal differences), rather than those between Catholics and Protestants from the evangelical denominations (encouraging strict adherence to religious doctrines) (see Steensland et al. 2000). Indeed, among evangelical denominations, some subgroups tend to share stronger views on biblical authority, rejecting science, and being theologically more conservative (for a review, see Woodberry and Smith 1998). 


\section{Autonomous and Heteronomous Norm Integrations Among Catholics and Protestants}

\section{Theoretical Underpinning}

In the field of sociology of crime, studies have shown how conformity to the law echoes the above concepts of intrinsic and extrinsic motivation. Specifically, the role of "self-control" has been opposed to that of "social integration" as mediators of the violation of rules. Self-control is viewed as personal self-restraint acquired through childhood socialization and maintained thereafter as an internal control on behavior regulation (Gottfredson and Hirschi 1990). Social integration is viewed as a psychological strength that binds people to others, increasing the conformity to group norms and reducing infringement of the law (Durkheim [1967] 1967).

Religion has been found to promote socially normative behaviors, including a lower likelihood of engaging in crime and delinquency (e.g., Ulmer et al. 2012). Religion is thought to foster self-regulation via the above-mentioned mechanisms: self-control (refraining from an undesirable behavior as a result self-monitoring) and social control (refraining from an undesirable behavior as a result of monitoring by the members of one's religious community) (McCullough and Willoughby 2009; Ulmer et al. 2012). As far as social control is concerned, God himself can be considered as the ultimate source of surveillance, that is, "the eye in the sky" watching us. As a matter of fact, when the concept of God is activated, believers tend to act in a more moral (Chan, Tong, and Tan 2014), socially desirable (Gervais and Norenzayan 2012), and self-controlled way (Rounding et al. 2012).

Participating in religious activity (e.g., attending church) can play a similar role. On the one hand, religious activity helps people to internalize moral commitments that motivate selfregulation of one's own behavior (Perrin 2000). On the other hand, religious activity builds personal relationships among believers, who may exert mutual social control (Stark and Bainbridge 1996). Thus, with such religious activities, both dimensions (i.e., self- and social control) may be active, but operate differently.

In social psychology, the study of social norms has followed similar paths, albeit focusing on the nature of the norms themselves. Codol (1975) made a distinction between ideal and factual norms. ${ }^{1}$ Norms of the first kind are followed because of the intrinsic moral value that individuals personally attribute to them. Norms of the second kind are those that the majority follows as a matter of fact and that people agree with because of normative pressure. Milgram's (1974) experiments may be the most impressive set of studies showing that people can intensively submit to an authority that exerts social control. These two types of norms can respectively be interpreted according to an internal control (the intrinsic value granted to the norm by the self) and an external one (the majority of the group or one of its legitimate authorities). Furthermore, adhering to these social norms could be nothing else than a consequence of differences between intrinsic and extrinsic motivations: individuals might follow a norm because it has been integrated, or because the authority responsible for the norm exercises social control.

Following these ideas, it is legitimate to think that individuals from a Protestant backgroundas they tend to integrate norms in a more autonomous way-might regulate behaviors through self-control, rather than the control of an authority. Conversely, individuals from a Catholic background - as they tend to follow norms through a heteronomous relationship with authoritymay regulate behaviors according to social control rather than self-control. Note that we are not arguing that faith in itself predicts different reactions to social control; beyond the religious content itself, being socialized in a Protestant versus a Catholic family environment (without

\footnotetext{
${ }^{1}$ See also Cialdini, Reno, and Kalgreen (1990), who made an analogous but not homologous distinction between injunctive and descriptive norms.
} 
even necessarily being a believer oneself) should predict different integration of authority-related social norms.

\section{Indirect Evidence}

Three kinds of results suggest the plausibility of different norm integration between Catholics and Protestants. A first one comes from the relationship between Christianity and voluntary association membership. Religion is a social network that may lead people to voluntarily work to help others. As this kind of behavior does not depend at all on an authority, one might expect that those who internalize the religious norms will endorse them more. As a matter of fact, Catholics were found to be less inclined to freely participate in secular associations than Protestants (Pui-Yan 2006).

Second, results in the domain of religious schooling show that adults who attended a Catholic school are less religious than those who attended Protestant ones; it suggests that frequenting Catholic schools has little effect on people's religiosity once they are no longer submitted to the religious authorities (Uecker 2009).

Third, bearing in mind that corruption corresponds to a private behavior that is difficult to be controlled by authorities, cross-country studies show that the higher the proportion of Protestants in a country's population, the lower the perceived corruption (Herzfeld and Weiss 2003).

The aforementioned studies neither manipulated social control nor proposed any variable explaining the differences between people from Protestant and Catholic backgrounds in terms of moral-related behavior regulation. The present experiments aim at addressing these issues, using a behavior that implies the violation of a strong moral norm, namely, cheating (see Cummins 1999). We focused on two specific forms of cheating, namely, copying off someone's work (Study 1) and lying for self-gain (Study 2), which were both found to be perceived as particularly morally unacceptable (Garavalia et al. 2007; Jensen et al. 2002). Surveys conducted over three decades have consistently shown that religion (church) is seen as the second provider-after parents-of rules that forbid cheating, including looking at someone else's work during an exam, stealing something, or lying (Schab 1991). More directly, a conception of God as a punishing figure, and thus a controlling one, leads to less cheating (Shariff and Norenzayan 2011). We therefore formulated a moderation hypothesis (tested in Studies 1 and 2) as well as a mediated moderation one (tested in Study 2):

H1: Catholics should cheat less when social control is salient than when it is not, whereas Protestants should be less-or even not-sensitive to social control;

H2: this interactive effect should be mediated by Catholics' lower intrinsic (and/or higher extrinsic) religiousness, compared to Protestants.

\section{STudy 1}

\section{Method}

\section{Participants}

The ethics committee of the first author's university gave approval for the experiments. Power analysis showed that at least 50 participants were needed to detect a small-to-medium interaction $(d=.4)$ in a mixed within-between design with a power of .8 (Faul et al. 2009). Fifty-seven individuals were recruited on a voluntary basis. We targeted a Swiss student housing historically founded by friars to increase our chance to reach Christians. Participants were 17 Protestants, 30 Catholics, and three atheists. Five participants, categorizable neither as Protestant nor Catholic, 
as well as two others who guessed the aim of the experiment, were removed. ${ }^{2}$ Moreover, two atheists were categorized according to the religious affiliation of their parents (the third atheist had Buddhist parents). Results are essentially similar with or without these two participants. The final sample included 18 Protestants and 31 Catholics ( 25 women, 24 men, $M_{\text {Age }}=22.86, S D=3.48$ ).

\section{Procedure}

Before the experiment, two pilot studies were conducted to build the material and ensure it would have the desired properties.

\section{Pilot Study 1}

Twenty participants, recruited in the first author's university building, were asked to guess more than 100 noncommon words, given a list of word hints. Out of the participants' answers, words were classified according to the following criteria: (i) easy words were those that at least 90 percent of participants guessed correctly; and (ii) difficult words were those that at least 90 percent of participants could not guess. Ten easy words were randomly picked out of all words meeting the first criteria and were used in the experiment (see Appendix A). All the words meeting the second criteria - together with their corresponding hints-were retained and used in Pilot Study 2.

\section{Pilot Study 2}

Pilot Study 2's goal was to select 10 difficult words for Study 1. Twenty other participants (recruited in the same way) were given the hints for the difficult words selected in Pilot Study 1. For each hint, participants had to guess the correct word out of four given options, namely, three semantically similar words and "I don't know." The latter option was added to prevent participants from picking an answer randomly (which would have had artificially increased the number of accurate matches). The 10 hints for which most participants guessed the correct word were used in the experiment (see Appendix B). For these 10 hints, the rates of correct guesses ranged from 50 percent to 90 percent. In sum, the selected difficult words were those that people could not guess when given the definition, but that they could identify easily as being the correct word when seeing it.

\section{Main Study}

Participants in Study 1 were told that the purpose of the research was to investigate verbal intellectual capabilities. They believed that another individual participated at the same time in the study. In fact, the other person was a trained accomplice.

The experiment consisted of two verbal tasks, both composed of a list of 10 hints. Each list included five easy hints (selected from Pilot Study 1) and five difficult ones (selected from Pilot Study 2), with easy hints relating to words that individuals guessed when provided with their definition and difficult hints relating to words that they could only recognize as being the correct answer when seeing them. Each participant saw the two lists (i.e., a within-participants design). However, the lists were randomly counterbalanced between participants, and the hints were randomized within lists. The easy and difficult hints were not labeled as such.

Both individuals - the participant and the accomplice-were seated next to each other on two adjacent tables. A large opaque screen separated them up to 30 centimeters away from the top end of the tables. Although this made it unfeasible for individuals to see each other (and, by implication, the other's answer sheet), it was possible for the participant to see the responses of the accomplice if he/she moved the sheet to the top of the table.

The experimenter held a chronometer and told participants that they had eight minutes to complete each task ( 48 seconds per word). This time limit was chosen because it seemed sufficient

\footnotetext{
${ }^{2}$ One Buddhist, one Hindu, two being both Catholic and Protestant, and one missing value.
} 
for participants to realize that, once having guessed the easy words, they would not be able to guess the remaining difficult words (due to the level of difficulty). For each task, the accomplice pushed forward his answer sheet to the top of the table after four minutes, therefore signaling that he had finished the task. As alluded to above, at this point, the accomplice's sheet was suddenly visible to the participant. The accomplice always filled in all the correct answers on the sheet.

Social control manipulation was a within-participant variable. The manipulation was the presence (vs. absence) of the authority during the task, that is, the experimenter. For half of the participants $(n=23)$, the experimenter, feigning an important matter, left the room during the first task, 30 seconds after the accomplice had pushed his answer sheet forward. Only two participants realized that this event was staged and were therefore excluded from the analyses. The experimenter came back 10 seconds before the end of the task to tell participants that the time for the first task was up, and then stayed for the second one. For the other half of the participants $(n=26)$, the order was reversed: the experimenter was present during the first task and absent during the second one. It is worth noting that, while in the room, the experimenter spent his time reading, looking through the window, or at his chronometer. He never looked directly at the participants, in order to avoid a sense of direct surveillance. This way, hypothetically, cheating without being caught was feasible even when the experimenter was present.

\section{Variables}

\section{Cheating Behavior}

From the pilot studies, difficult words are known to be almost impossible to guess, but easily recognized when seen. Because participants could look at the answers of the accomplice, cheating was measured by the number of difficult words correctly guessed reported on their own answer sheet $(M=2.65, S D=1.92)$. It is worth noting that the number of easy words found $(M=$ $9.69, S D=.62)$ neither predicted the check measure in the present preliminary analyses nor was predicted by social control and religion in the main analyses $(p s \geq .32)$.

\section{Self-Reported Check of Cheating Behaviors}

At the end of the session, on a seven-point scale $(1=$ not at all and $7=$ completely $)$, participants answered an item ("Have you tried to copy some of the other individual's responses in order to improve your score?") that aimed at assessing the validity of our in-task cheating measure $(M=2.27, S D=1.72)$. Such self-reported measures of cheating have long been known to be positively correlated with behavioral measures of cheating (Erickson and Smith 1974).

\section{Results}

\section{Check of the Number of Difficult Words Solved as a Cheating Measure}

In a linear regression model, the total number of difficult words guessed was found to be positively associated with the self-reported check of cheating behavior, $B=.35,95 \% \mathrm{CI}[.11, .59]$, $F(1,47)=8.70, p=.005, \eta^{2} \mathrm{p}=.15$ percent. ${ }^{3}$ In other words, the more difficult words participants guessed, the more they recognized having cheated. This confirmed the validity of our cheating measure.

\section{Overview of the Linear Regression Analyses}

The experimental design is a 2 (social control: with vs. without) $\times 2$ (religion: Protestants vs. Catholics), with the former independent variable as a within-participant variable and the latter

\footnotetext{
${ }^{3}$ From here, "95\% CI" is omitted and square brackets signal a 95 percent confidence interval; moreover, partial eta squared corresponds to the effect size, that is, the proportion of variance specifically explained by the inclusion of the variable.
} 
Figure 1

Number of difficult words found (cheating behaviors; estimated means) as a function of religious group (Protestants vs. Catholics) and condition (without vs. with social control)

$\square$ Without social control $\square$ With social control

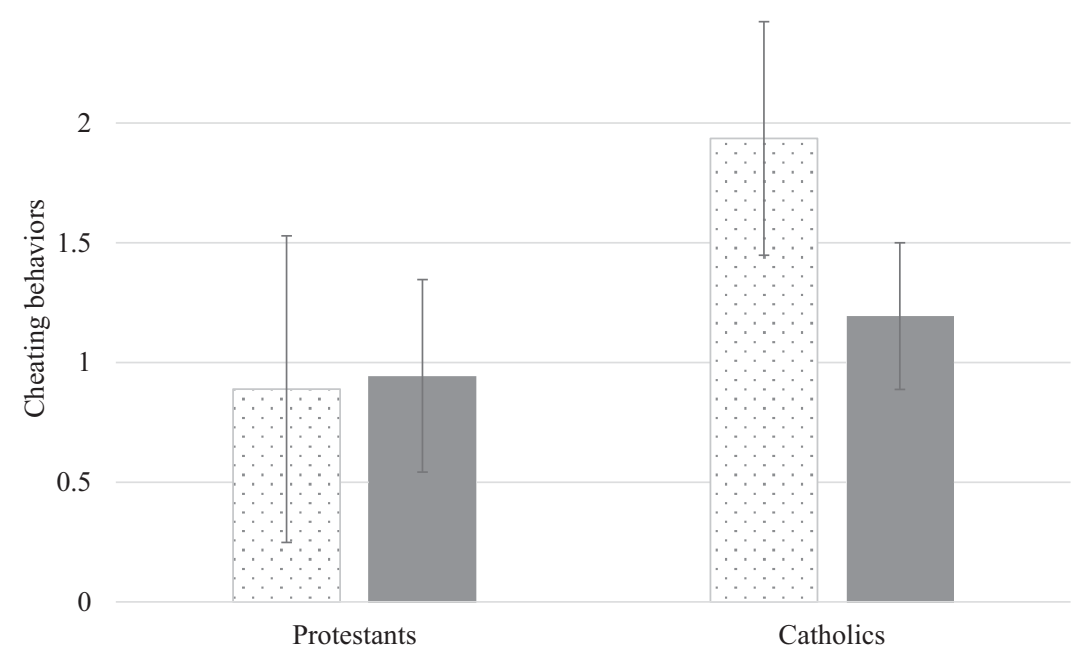

Note: Study 1. Error bars represent 95 percent confidence intervals.

as a between-participant variable. To test our predictions, we therefore regressed the difference of difficult words found between the social control conditions on the religious background of the participant (coded -.5 for Protestant and +.5 for Catholics). Note that the coefficient estimate of the between-participant variable (religion) corresponds here to the interaction effect (the difference between the conditions in terms of cheating, as a function of religion).

\section{Complete Analyses of Covariance}

Before running the main analysis, we conducted a complete analysis of covariance from the aforementioned model (Yzerbyt, Muller, and Judd 2004) in order to determine the potential need to control for additional variables, namely, sex, mean-centered age, the order of presentation of the word lists, and that of the conditions (experimenter being first absent vs. present). Results did not reveal any significant effects of these variables $(F \mathrm{~s}<1)$. Therefore, these terms were not further considered.

\section{Effect of Religion and Social Control on Cheating Behaviors}

Consistent with our expectation, analyses revealed an interaction between the religious group and social control: $B=-.80[-1.58,-.02], F(1,47)=4.20, p=.046, \eta_{\mathrm{p}}^{2}=.08$. Specifically, as expected and as seen in Figure 1, Catholics cheated more without social control $(M=1.94$ [1.45, 2.42]) than with social control $(M=1.19[.89,1.50]), B=-.74,[-1.22,-.27], F(1,47)=$ $9.92, p=.003, \eta_{\mathrm{p}}^{2}=.17$. Protestants, on the other hand, did not cheat more without social control, $M=.89,[.25,1.53]$ than with social control, $M=.94[.54,1.35], B=.06,[-.57, .68]$, $F<1$, n.s.

\section{Discussion}

In line with $\mathrm{H} 1$, social control (the presence vs. the absence of an authority) was found to reduce cheating behaviors for Catholics, but not for Protestants. 
A second study was conducted using a larger sample from the U.S. general population, which is much more diverse in terms of religious affiliation. Notably, atheists and agnostics from Catholic and Protestant families took part in the study. Both a specific religious socialization and a specific set of religious beliefs can convey the social norms regarding authority figures. In the former case, H1 would hold true for such nonbelievers having been raised in a Christian family, whereas in the latter, H1 would not hold true. A comparison between believers and nonbelievers from Christian families may give information on that matter.

Moreover, we used a slightly different operationalization of social control. In Study 1, social control was manipulated in an objective way (presence vs. absence of the authority). In Study 2, it was manipulated in a subjective way (salience vs. nonsalience of social control), while keeping constant the experimenter's physical absence. As the perception of social control-rather than the mere presence of an authority - should trigger Catholics' regulation of cheating behaviors, Study 1's findings were expected to be replicated.

Finally, an important issue remained to be addressed, namely, that of the mediating variable(s) of the observed interaction. Hence, Study 2 also aimed at testing the role of intrinsic-extrinsic religiousness in accounting for the moderation between religion and social control on cheating, that is, $\mathrm{H} 2$.

\section{STUdy 2}

\section{Method}

\section{Participants}

Power analysis showed that 200 participants were needed to detect a small-to-medium interaction $(d=.4)$ in a between-participants design with a power of .8 . Given that about 30 percent of Americans do not identify themselves as Christian (Pew Research Center 2014), we aimed at collecting at least 260 responses. Two hundred and seventy-seven Americans were recruited through Amazon Mechanical Turk. There were 82 Protestants, 45 Catholics, 15 from an unspecified Christian faith (due to missing values), and 105 atheists. Thirty-five participants, who could neither be categorized from a Protestant nor Catholic background, and two influential observations (Cooks' $D>.1$; Xie and Wei 2007) were excluded from analysis. ${ }^{4}$ As in Study 1 , when possible, atheists/agnostics were allocated to the religious affiliation of their parents (20 to Protestants and 28 to Catholics). The hypothesized interaction did not significantly differ as a function of the participants being believers or not (cf. preliminary analyses). The final sample comprised 102 participants from a Protestant background and 73 from a Catholic background (105 women, and 70 men; $M_{\mathrm{Age}}=32.89, S D=11.46$ ).

\section{Procedure}

In exchange for a $\$ 0.40$ payment, participants were invited to take part in an on-line study allegedly on "performance under time pressure." The task was adapted from Wiltermuth (2011). Participants had up to five minutes to solve nine word jumbles. They were informed that there was only one correct answer per jumble, and that they would receive a $\$ 0.10$ payoff for each word found. It was explained that the jumbles had to be solved in sequential order, so as to get the bonus for each of them, and that jumping an unsolved jumble to unscramble the next one would eliminate any potential bonus.

\footnotetext{
${ }^{4}$ Participants who could not be categorized were six Jews, three Buddhists, three from the Church of Christ, two Muslims, two Orthodox Christians, one Hindu, one Mormon, and 17 missing values. However, in keeping with the two influential observations, the hypothesized effect became marginal, $I R R=.48[.21,1.12], z=-1.70, p=.090$.
} 
Table 1: Word jumbles used in Study 2

\begin{tabular}{lcccc}
\hline Position & Jumble & Correct answer & $\begin{array}{c}\text { Frequency of } \\
\text { correct } \\
\text { answers }\end{array}$ & $\begin{array}{c}\text { Frequency of } \\
\text { answers reported } \\
\text { as correct }\end{array}$ \\
\hline 1 & UNHTED & HUNTED & $96.57 \%$ & $50.29 \%$ \\
2 & EOSHU & HOUSE & $92.57 \%$ & $9.71 \%$ \\
3 & UNALGT & n/a & $0 \%$ & $9.14 \%$ \\
4 & YTHOIRD & THYROID & $41.71 \%$ & $5.71 \%$ \\
5 & OLARC & CORAL/CAROL & $68.00 \%$ & $4.57 \%$ \\
6 & JNIPMUG & JUMPING & $44.00 \%$ & $6.29 \%$ \\
7 & HGITWE & WEIGHT & $57.14 \%$ & $12.57 \%$ \\
8 & CLASLOU & CALLOUS & $46.29 \%$ & $1.71 \%$ \\
9 & YOMSEEVLD & SEMOVEDLY & $.57 \%$ & \\
\hline
\end{tabular}

Next to each jumble, there was a text box where the solution could be reported. Table 1 presents the nine word jumbles. As in Wiltermuth (2011), the first two jumbles were easily solvable (as a matter of fact, 90 percent of the participants reported correct answers to both), and the third jumble was unsolvable. The last six jumbles were solvable, although the last one was very difficult (i.e., "semovedly" is a rare synonym of "separately"). The fact that the five jumbles following the unsolvable third jumble were feasible provided an incentive to cheat, that is, to act as though one solved the third jumble. Unexpectedly, the average of jumbles solved was higher than two $(M=4.34, S D=2.06) .^{5}$

Once the time had expired, participants reported the number of consecutive jumbles solved. They were informed that they would receive the bonuses according to this report. To ensure the participants clearly understood the instructions, they were all reminded that the jumbles should be solved in the sequential order and that they should report " 1 " if they had solved the first jumble, "2" if they had solved the first two, and so on. This information was repeated here for the third time (i.e., in the general instructions, before the report, and during the report). Hence, it was very unlikely that participants did not understand the rule at this point. As only the first two jumbles were solvable, reporting more than two words was impossible without lying; thus, the higher the self-reported number of jumbles solved above two, the greater the amount of cheating.

The manipulation of the salience of social control was introduced with the question on the report. For half of the participants, we asked the following question: "Please indicate how many consecutive jumbles you have correctly unscrambled. You should know that the researcher might verify the answers that you will be providing here" (salience of a possible social control, $n=$ 77). For the other half, we only asked: "Please indicate how many consecutive jumbles you have correctly unscrambled," without any additional information (nonsalience of a possible social control, $n=98)$.

\footnotetext{
${ }^{5}$ The third jumble being unsolvable, it was indeed unexpected that some participants did not follow the instructions and tried to unscramble the further ones. There could be two reasons for this. On the one hand, given the time pressure created by the cover story, it is possible that these participants aimed at coming back to the third jumble after having solved the next ones (which could not be interpreted as an unequivocal nonobservance of the instructions). On the other hand, it is equally possible that these participants voluntarily chose to disrespect the rule (which could be interpreted as cheating). Hence, to avoid any alternative explanation of the measure, the number of jumbles actually solved was entered as a covariate in preliminary analysis to ensure that the effect observed-if any-was indeed a matter of reporting a higher number of jumbles than had been done, thus a matter of cheating.
} 
After having indicated their religion and answered a last series of questions, participants were debriefed. They all received a payment as if they had solved the nine jumbles.

\section{Variables}

\section{Cheating Behaviors}

The self-reported number of word jumble(s) solved above two was used as the cheating measure $(M=1.82, S D=2.31)$. A value of "zero" meant no cheating. A large proportion of participants were in that case (50.29 percent), showing a possible asymmetry in the distribution (see the overview of the regression analyses). Since the third jumble was unsolvable, a value of "one" indicated a dishonest report for a $\$ .10$ bonus. By extension, since the jumbles had to be solved consecutively, a value of "two" suggested a two-fold dishonest report for a $\$ .20$ bonus, a value of "three" a three-fold dishonest report for a $\$ .30$ bonus, and so on.

\section{Relative Intrinsic-Extrinsic Religiousness}

Participants answered Maltby and Lewis's (1996) revised version of the I-E scale $(1=$ not at all and $7=$ completely). Eight items measured intrinsic religiousness (e.g., "I try to live all my life according to my religious beliefs."; $\alpha=.95, M=3.33, S D=1.92$ ). Twelve others measured extrinsic religiousness (e.g., "Sometimes I have to ignore my religious beliefs because of what other people might think of me."; $\alpha=.85, M=2.85, S D=1.17$ ). As intrinsic and extrinsic religiousness were highly correlated $(r=.69, p<.001)$, we subtracted the latter from the former $(M=.49, S D=1.40)$. Creating such a difference-based index is a common practice in research on self-determination theory (e.g., self-concordance variable; Sheldon and Elliot 1999). A positive value indicated a prioritized inclination toward intrinsic religiousness, a negative value indicated a prioritized inclination toward extrinsic religiousness, and a value of zero indicated similar inclinations toward intrinsic and extrinsic religiousness.

\section{Self-Reported Indirect Admission of Cheating Behaviors}

At the end of the survey, on a seven-point scale $(1=$ not at all and $7=$ completely $)$, participants answered an item ("It is possible that I made a mistake while reporting my performance at the task."), indirectly checking that participants knew that their self-report number of the number of jumbles solved was a lie $(M=3.47, S D=2.27)$.

\section{Results}

A summary of the results is presented in Table 2 .

\section{Check of the Self-Reported Number of Jumbles Solved as a Cheating Measure}

In a linear regression model, the self-reported number of word jumble(s) solved above two was found to be positively associated with the propensity to admit to having possibly made a mistake, $B=.20,[.05, .34], F(1,173)=7.34, p=.007, \eta^{2}{ }_{\mathrm{p}}=.04$. This confirmed the validity of our cheating measure.

\section{Overview of the Regression Analyses}

Confirming the suspected asymmetry in distribution, the cheating behavior measure exhibited a moderated right skewness $(s k=.90)$ as well as quite a large peakness $(k=2.25)$. A Shapiro-Wilk's test—conducted on the residuals of a linear regression model—rejected the null hypothesis $(p>.06)$ of a normal distribution (Shapiro and Wilk 1965). With such a violation of the normality assumption, and given the fact that the outcome variable's mean and variance 


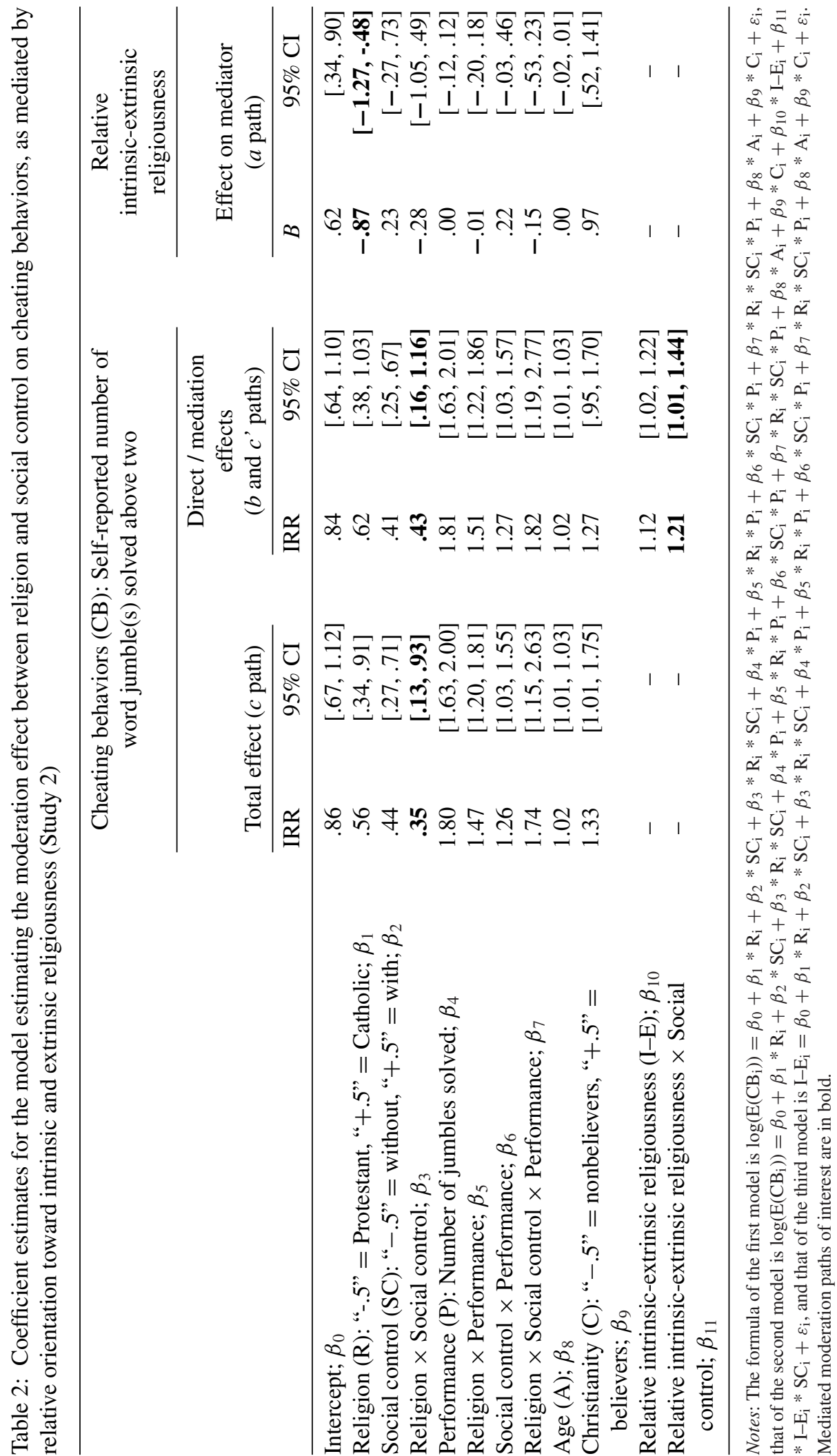


were in the same neighborhood, Poisson regressions were adapted (King 1988). ${ }^{6}$ The coefficient estimate for Poisson regressions is expressed as an incidence rate ratio, such that $I R R<1$ indicates a negative effect, $I R R>1$ indicates a positive effect, and $I R R$ not significantly different from 1 indicates a nonrejection of the null hypothesis. An $I R R$ can also be read as an effect size indicator (Faul et al. 2009). In this study, the self-reported number of jumbles solved (i.e., cheating behaviors) was regressed on the variables religious group (coded " -.5 " for Protestant and " +.5 " for Catholics), social control (coded " -.5 " for nonsalient and " +.5 " for salient), and their interaction.

\section{Preliminary Analysis}

Before running the main analysis, a complete analysis of covariance aimed at determining the need to control for additional variables, namely, sex, mean-centered age, as well as the fact that the participant reported being a believer or not (coded " -.5 " for believers and " +.5 " for the nonbelievers being from a Christian family), and mean-centered task performance (see Footnote 5). Analysis revealed main effects of all these variables except sex, as well as interaction effects between performance and social control and/or religious group. Hence, these significant terms were kept in the main analyses (see Table 2).

More fine-grained analysis revealed that the distinction between believers and nonbelievers neither interacted with the condition nor with the religious group $(Z s<1)$. In line with Study 1's findings, simple effect analysis showed that the hypothesized interaction between social control and religious group remained significant for participants who indicated being believers, $B=.31$ $[.12, .85], \mathrm{z}=-2.29, p=.022$. The fact that the interaction held for the whole sample suggests that socialization within a Catholic or a Protestant family matters more here than whether or not a participant believed in God. Thus, the interaction terms involving this variable were not further considered.

\section{Effect of Religion and Social Control on Cheating Behaviors}

A main effect of social control was found, $I R R=.44[.27, .71], \mathrm{z}=-3.31, p<.001$, as well as a main effect of the religious group, $I R R=.56[.34, .91], Z=-2.34, p=.019$. However, these main effects were not necessarily meaningful given the presence of an interaction (see Figure 2).

Indeed, in line with H1, and replicating Study 1's findings, the interaction between the religious group and social control was significant, $I R R=.35[.13, .93], \mathrm{z}=-2.10, p=.036$. Specifically, as seen in Figure 2, simple slope analysis revealed that Catholics cheated less when social control was salient $(M=.33[.14, .75])$, than when it was not $(M=1.26[.90,1.78])$, $I R R=.26[.11, .64], z=-2.96, p=.003$. Such a difference was not observed for Protestants, $\operatorname{IRR}=.74[.50,1.09], z=-1.54, p=.124$.

Moreover, task performance was found to predict cheating, as well as to interact with our variables of interest (see Table 2 for the details of the result). More precisely, the hypothesized effect increased as actual performance decreased. It might simply result from a methodological specificity of the task: for participants having unscrambled an elevated number of words (especially after the third one), the self-reported number of jumbles solved reflects their actual performance more than their cheating intentions. As there are fewer unsolved slots to report as being solved, the room to cheat is mechanically reduced, limiting the discriminative power of the cheating measure.

\footnotetext{
${ }^{6}$ To relax the equivariance assumption, negative binomial regression modeling could be used. In our case, the estimates obtained from negative binomial regressions were descriptively similar to the estimates obtained from Poisson regressions reported in the main text. Specifically, the difference between the incidence rate ratio of the hypothesized total effect from the negative binomial model (IRR $=.35, p=.092$ ) and the incidence rate ratio of the hypothesized effect of the Poisson regression model $(\mathrm{IRR}=.38, p=.036)$ was not significant, $\chi(1)<1, p=.556$.
} 
Figure 2

Self-reported number of word jumbles solved above Two (cheating behaviors; expected value) as a function of religious group (Protestants vs. Catholics) and condition (nonsalience vs. salience of social control)

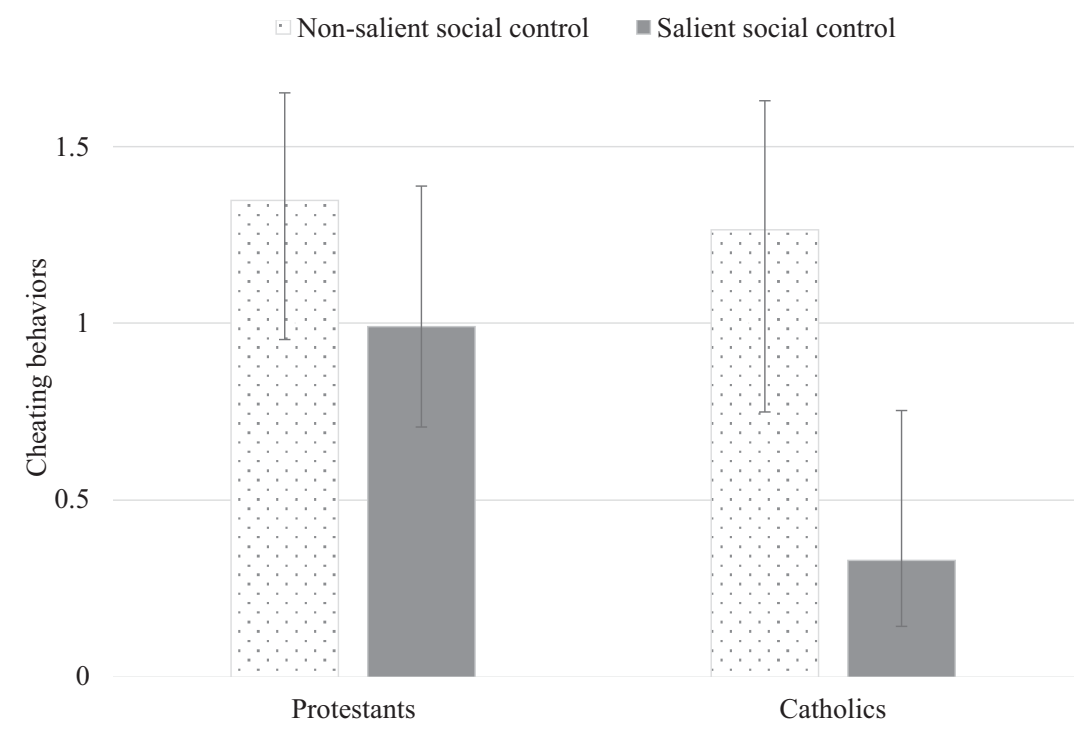

Note: Study 2. Error bars represent 95 percent confidence intervals.

Figure 3

Moderation effect between religion and social control on cheating behaviors, as mediated by relative orientation toward intrinsic and extrinsic religiousness

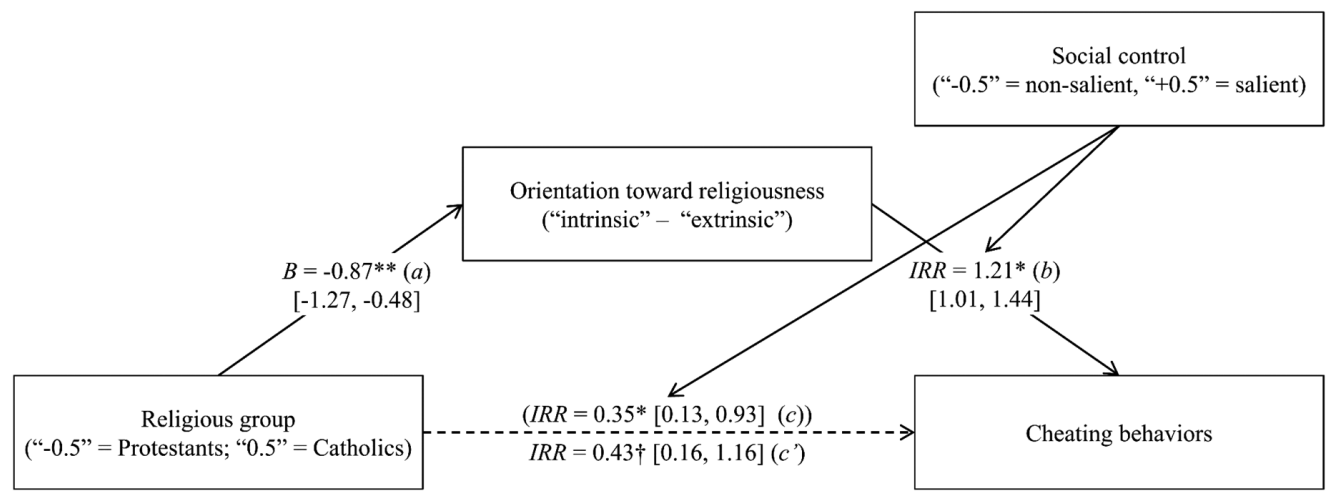

$* * p<.001, * p<.05, \dagger p=.1$.

\section{Mediated Moderation Analysis}

Mediated moderation analyses were carried out to test whether the total interaction effect between the religious group and social control on cheating ( $c$ path) could be explained by the relative orientation toward intrinsic-extrinsic religiousness (see Figure 3).

As a first step, relative intrinsic-extrinsic religiousness was linearly regressed on the same nine predictors as before. Analysis revealed an effect of the religious group, $B=-.87[-1.27$, $-.48], F(1,165)=18.75, p<.001, \eta_{\mathrm{p}}^{2}=.10(a$ path $)$, such that Protestants reported being more oriented toward intrinsic than extrinsic religiousness $(M=.62[.34, .90])$, whereas Catholics showed the reversed tendency $(M=-.25[-.56, .05])$. 
As a second step, we ran the same Poisson regression analysis as conducted earlier (using cheating as the dependent variable), and added mean-centered relative intrinsic-extrinsic religiousness and its interaction with social control as predictors. The effect of social control was moderated by relative intrinsic-extrinsic religiousness, $I R R=1.21[1.01,1.44], z=2.05, p=.040$ ( $b$ path). Salience of social control predicted less cheating when participants were intrinsically oriented $(-1 \mathrm{SD}), \operatorname{IRR}=.31[.17, .57], \mathrm{z}=-3.85, p<.001$, than when they were extrinsically oriented $(+1 \mathrm{SD}), \operatorname{IRR}=.53[.31, .90], \mathrm{z}=-2.35, p=.019$. The interaction between the religious group and social control became marginal, $I R R=.43[.16,1.16], \mathrm{z}=-1.67, p=.095$ (c path).

The calculation of the conditional indirect effect is not as straightforward for count outcome variables as it is for linear outcome variables (see Hayes 2013). We calculated it using medflex, an R package relying on the counterfactual mediation framework (Steen et al. 2017). The social control manipulation was found to be indirectly more associated with cheating through an increase in extrinsic (vs. intrinsic) religiousness for Catholics than for Protestants, albeit the effect fell short of significance, $\operatorname{IRR}=.76[.57,1.01], \mathrm{z}=-1.88, p=.060$.

\section{Discussion}

In line with $\mathrm{H} 1$ and replicating Study 1's findings with a different paradigm, in Study 2, social control was found to reduce cheating behavior among individuals from a Catholic background, but not among those from a Protestant background.

Interestingly, no difference was found between believers and nonbelievers, which suggests that the effect may be due to religious upbringing rather than religious belief in and of itself. This would be consistent with the idea that family religion is an important factor determining the transgenerational transmission of values (Hoge, Petrillo, and Smith 1982). Specifically, being raised in a Catholic family (and, by extension, in its related social network) shapes specific values, such as respect for authority and norm compliance, whereas being raised in a Protestant family encourages intellectual autonomy and self-reliance (Ellison and Sherkat 1993). Such socialization processes might explain why social control is more effective for individuals from a Catholic background, regardless of their personal religious conviction. However, as this reasoning is based on a null result (an absence of difference between believers and nonbelievers), further studies are needed before a definitive conclusion can be drawn.

Moreover, in line with $\mathrm{H} 2$, orientation toward intrinsic-extrinsic religiousness was found to mediate this moderation effect. Simply put, a lower relative orientation toward intrinsic religiosity accounted for Catholics' higher sensitivity to the effect of social control on cheating. However, the conditional, indirect effect fell short of significance. Thus, Study 2's mediation result has to be considered carefully. It offers suggestive (rather than conclusive) evidence in support of the full mediated moderation model that needs to be replicated.

\section{General Discussion}

Some essential differences between Study 1 and Study 2 should be highlighted. First, social control was operationalized via the actual presence of authority in Study 1, whereas Study 2 contained only an implied element of social control. The similarity of findings between the two studies speaks in favor of the psychological nature of the phenomenon. The mere impression of social control is most likely what directs Catholics (vs. Protestants) toward endorsing more desirable moral behaviors.

Second, Protestants were found to cheat less than Catholics in Study 1, whereas the reverse was true in Study 2. This illustrates that Protestants and Catholics do not differ per se in terms of cheating inclination, with the latter cheating more than the former (or vice-versa). More 
specifically, Protestants - given their orientation toward intrinsic (vs. extrinsic) religiousnessappraise moral-related behaviors independently of their perception of social control, which may alternatively lead to more or less cheating behavior. For Protestants, the context-invariant level of cheating might depend on the nature of the norm violation (copying off someone's work in Study 1, versus lying for self-gain in Study 2) (see Garavalia et al. 2007), or the achievement context (low-stake test in Study 1, versus cash incentive in Study 2) (see Weber [1992] 1992). Regardless of the reasons, these findings suggest that behavior regulation is grounded in an internal source of control (the self) for Protestants, and in an external source of control (the monitoring of an authority) for Catholics. This is consistent with research on objective self-awareness, showing that self-focused individuals tend to act more consistently and are less likely to be moral hypocrites (for a review, see Silvia and Duval 2001).

\section{Limitations}

Three limitations should be acknowledged. First, a word of caution with respect to the extension of the findings to all existing Catholic/Protestant subgroups should be added. Given our theoretical framework, it is indeed conceivable that some isolated and specific groups of Protestants could exhibit behaviors at odds with the results of the present studies. For instance, small and cohesive Protestant groups could be more responsive to social control than those in our samples, to the extent that their church is organized in a hierarchical and authoritarian way.

Second, one may argue that our manipulations affected the appraisal of the likelihood of being caught cheating. However, one's perceptions of the risk of being caught and sanctioned are a key determinant of the level of perceived social control (for an illustration with juvenile delinquency, see Kaplan, Gostjev, and Johnson 2013). Thus, it is likely that Catholics might have assessed such a risk as being greater in the social control condition, regulating their behaviors accordingly. This is particularly true in Study 1: the physical presence of the experimenter might have increased the risk of being caught (despite the fact that he pretended to be busy with other matters). Interestingly, there are some hints in the literature suggesting that Catholics are more sensitive to risk (e.g., gun-related risks of incidents; Kahan et al. 2007), and future research might investigate whether risk sensitivity contributes to explaining why Catholics are more responsive to social control.

Third, one might have concerns regarding the validity of the cheating measure used in Study 2, that is, the self-reported number of jumbles solved above two. As most participants unscrambled the jumbles following the unsolvable third jumble, one cannot formally exclude that they misunderstood the instructions and reported the raw (rather than the consecutive) number of jumbles solved. In such, the cheating measure would be ambiguous. Yet, three counterarguments can be presented. First, Study 2's jumble task was used in previous research, in which the overreport of the performance was taken as a behavioral measure of cheating (e.g., Gino and Mogilner 2014: Hoffmann et al. 2015; Wiltermuth 2011). Second, in our experiment, the self-reported number of jumbles solved above two was associated with an indirect propensity to admit having possibly lied, speaking in favor of the validity of the measure (see Erickson and Smith 1974). Third, the hypothesized interaction observed in Study 1 with a more unequivocal measure of cheating (copying off someone's work) was the same as the interaction observed in Study 2 (i.e., Catholics being more responsive to social control), providing extra support to the idea that Study 2's outcome variable is indeed a cheating measure.

\section{IMPLiCATIONS AND CONCLUSION}

This work raises doubts as to the unconditional effectiveness of public policies based on social control. As is often the case, ensuring compliance to norms requires some control from 
the authorities. In school, policies based on cheating detection algorithms (notably based on test score fluctuations) were developed to reduce the prevalence of academic dishonesty (Jacob and Levitt 2003). Beyond the issue of education, other examples include the use of road checkpoint and radar in preventing car accidents (Asbridge, Smart, and Mann 2006), security cameras in reducing misconduct (van Rompay, Vonk, and Fransen 2009), and even mass surveillance electronic technology in preventing crime or terrorism (Ogura 2006). Such instruments of social control can be linked to Bentham's Panopticon, a prison in which convicts know that they could be observed but do not know whether they are currently observed or not. Foucault (1975) used the Panopticon metaphor to describe a disciplinary system based on social control. Given our results, one might query whether concrete Panopticon-like surveillance systems might have any deterrent effect within certain groups, such as Protestants or individuals from a Protestant background. The same reasoning could be extended to other social groups not regulating their self-presentation with regard to social norms (Berinsky 2004), or to societies having weak social norms and an elevated tolerance of deviant behavior (i.e., the so-called loose societies; see Gelfand et al. 2011; Triandis 1989).

\section{REFERENCES}

Adorno, Theodor W., Else Frenkel-Brunswik, Daniel Levinson, and Nevitt Sanford. 1950. The authoritarian personality. New York: Harper and Row.

Allport, Gordon W. 1950. The individual and his religion. New York: Macmillan.

Allport, Gordon W. and Michael J. Ross. 1967. Personal religious orientation and prejudice. Journal of Personality and Social Psychology 5(4):432-43.

Asbridge, Mark, Reginald G. Smart, and Robert E. Mann. 2006. Can we prevent road rage? Trauma, Violence, and Abuse 7(2):109-21.

Berinsky, Adam J. 2004. Can we talk? Self-presentation and the survey response. Political Psychology 25(4):643-59.

Chan, Kai Q., Eddie M. W. Tong, and Yan L. Tan. 2014. Taking a leap of faith reminders of God lead to greater risk taking. Social Psychological and Personality Science 5(8):901-09.

Christophe, Paul. [1982-1983] 2000. 2000 ans d'histoire de l'Eglise [2000 years of Church history]. Paris: DroguetArdant.

Cialdini, Robert B., Raymond R. Reno, and Carl A. Kallgren. 1990. A focus theory of normative conduct: Recycling the concept of norms to reduce littering in public places. Journal of Personality and Social Psychology 58(6):1015-26.

Codol, Jean-Paul. 1975. On the so-called "superior conformity of the self" behavior: Twenty experimental investigations. European Journal of Social Psychology 5(4):457-501.

Cohen, Adam B. 2015. Religion's profound influences on psychology morality, intergroup relations, self-construal, and enculturation. Current Directions in Psychological Science 24(1):77-82.

Cohen, Adam B. and Peter C. Hill. 2007. Religion as culture: Religious individualism and collectivism among American Catholics, Jews and Protestants. Journal of Personality 75(4):709-42.

Cummins, Denise D. 1999. Cheater detection is modified by social rank: The impact of dominance on the evolution of cognitive functions. Evolution and Human Behavior 20(4):229-48.

Deci, Edward L. and Richard M. Ryan. 1985. Intrinsic motivation and self-determination in human behavior. New York: Plenum Press.

Donahue, Michael J. 1985. Intrinsic and extrinsic religiousness: Review and meta-analysis. Journal of Personality and Social Psychology 48(2):400-19.

Durkheim, Émile. [1897] 1967. Le suicide. Etude de sociologie. [Suicide: A study in sociology] Paris: Presses Universitaires de France.

Ellison, Christopher G. and Darren E. Sherkat. 1993. Obedience and authority: Religion and parental values reconsidered. Journal for Scientific Study of Religion 32(4):313-29.

Erickson, Maynard L. and Walton N. Smith, Jr. 1974. On the relationship between self-reported and actual deviance: An empirical test. Humboldt Journal of Social Relations 1(2):106-13.

Faul, Franz, Edgar Erdfelder, Axel Buchner, and Albert-Georg Lang. 2009. Statistical power analyses using G* Power 3.1: Tests for correlation and regression analyses. Behavior Research Methods 41(4):1149-60.

Foucault, Michel. 1975. Discipline and punish: The birth of the prison. New York: Vintage.

Garavalia, Linda, Elizabeth Olson, Emily Russell and Leslie Christensen. 2007. How do students cheat. In Psychology of academic cheating, edited by Eric M. Anderman and Tamera B. Murdock, pp. 33-58. Burlington, MA: Elsevier Academic Press. 
Gelfand, Michele J., Jana L. Raver, Lisa Nishii, Lisa M. Leslie, Janetta Lun, Beng Chong Lim, Lili Duan, Assaf Almaliach, Soon Ang, Jakobina Arnadottir, Zeynep Aycan, Klaus Boehnke, Pawel Boksi, Rosa Cabecinhas, Darius Chan, Jagdeep Chhokar, Alessia D’Amato, Montse Ferrer, Iris C. Fischlmayr, Ronald Fischer, Marta Fulop, James Georgas, Emiko S. Kashima, Yoshishima Kashima, Kibum Kim, Alain Lempereur, Patricia Marquez, Rozhan Othman, Bert Overlaet, Penny Panagiotopoulou, Karl Peltzer, Lorena R. Perez-Florizno, Larisa Ponomarenko, Anu Realo, Vidar Schei, Manfred Schmitt, Peter B. Smith, Nazar Soomro, Erna Szabo, Nalinee Taveesin, Midori Toyama, Evert Van de Vliert, Naharika Vohra, Colleen Ward, and Susumu Yamaguchi. 2011. Differences between tight and loose cultures: A 33-nation study. Science 332(6033):1100-04.

Gervais, Will M. and Ara Norenzayan. 2012. Like a camera in the sky? Thinking about God increases public self-awareness and socially desirable responding. Journal of Experimental Social Psychology 48(1):298-302.

Gino, Francesca and Cassie Mogilner. 2014. Time, money, and morality. Psychological Science 25(2):414-21.

Gottfredson, Michael R. and Travis Hirschi. 1990. A general theory of crime. Stanford, CA: Stanford University Press.

Hayes, Andrew F. 2013. Introduction to mediation, moderation, and conditional process analysis: A regression-based approach. New York: Guilford Press.

Herzfeld, Thomas and Christoph Weiss. 2003. Corruption and legal (in)effectiveness: An empirical investigation. European Journal of Political Economy 19(3):621-32.

Hoffmann, Adrian, Birk Diedenhofen, Bruno Verschuere, and Jochen Musch. 2015. A strong validation of the crosswise model using experimentally-induced cheating behavior. Experimental Psychology 62(6):403-14

Hoge, Dean R., Gregory H. Petrillo, and Ella I. Smith. 1982. Transmission of religious and social values from parents to teenage children. Journal of Marriage and the Family 44(3):569-80.

Jacob, Brian A. and Steven D. Levitt. 2003. Rotten apples: An investigation of the prevalence and predictors of teacher cheating. Quarterly Journal of Economics 118(3):843-77.

Jensen, Lene Arnett, Jeffrey Jensen Arnett, S. Shirley Feldman, and Elizabeth Cauffman. 2002. It's wrong, but everybody does it: Academic dishonesty among high school and college students. Contemporary Educational Psychology 27(2):209-28.

Kahan, Dan M., Donald Braman, John Gastil, Paul Slovic, and C. K. Mertz. 2007. Culture and identity-protective cognition: Explaining the white-male effect in risk perception. Journal of Empirical Legal Studies 4(3):465505 .

Kaplan, Howard B., Feodor A. Gostjev, and Robert J. Johnson. 2013. Social psychological perspectives on deviance. In Handbook of social psychology, edited by John DeLamater and Amanda Ward, pp. 563-94. New York: Springer.

King, Gary. 1988. Statistical models for political science event counts: Bias in conventional procedures and evidence for the exponential Poisson regression model. American Journal of Political Science 32(3):838-63.

Maltby, John and Christopher A. Lewis. 1996. Measuring intrinsic and extrinsic orientation toward religion: Amendments for its use among religious and non-religious samples. Personality and Individual Differences 21(6):937-46.

McCullough, Michael E. and Brian L. B. Willoughby. 2009. Religion, self-regulation, and self-control: Associations, explanations, and implications. Psychological Bulletin 135(1):69-93.

Milgram, Stanley. 1974. Soumission à l'autorité. [Obedience to authority]. Paris: Calmann-Lévy.

Minois, Georges. 1991. L'Eglise et la Science: Histoire d'un malentendu. De Galilée à Jean-Paul II [The Church and science: The story of a misunderstanding. From Galileo to John Paul II]. Paris: Fayard.

Ogburn, William F. and Meyer F. Nimkoff. 1940. Sociology. Boston: Houghton and Mifflin.

Ogura, Toshimaru. 2006. Electronic government and surveillance-oriented society. In Theorizing surveillance, edited by David Lyon, pp. 270-95. Portland, OR: Willan.

Perrin, Robin D. 2000. Religiosity and honesty: Continuing the search for the consequential dimension. Review of Religious Research 41(4):534-44.

Pew Research Center. 2014. Religious landscape survey. Available at $<$ http://www.pewforum.org/religious-landscapestudy/>. Accessed July 12, 2017.

Pui-Yan, Lam. 2006. Religion and civic culture: A cross-national study of voluntary association membership. Journal for the Scientific Study of Religion 45(2):177-93.

Putney, Snell and Russell Middleton. 1961. Rebellion, conformity, and parental religious ideologies. Sociometry 24(2):125-35.

Rokeach, Milton. 1960. The open and closed mind. New York: Basic Books.

Rounding, Kevin, Albert Lee, Jill A. Jacobson, and Li-Jun Ji. 2012. Religion replenishes self-control. Psychological Science 23(6):635-42.

Ryan, Richard M., Scott Rigby, and Kristi King. 1993. Two types of religious internalization and their relations to religious orientations and mental health. Journal of Personality and Social Psychology 65(3):586-96.

Schab, Fred. 1991. Schooling without learning: Thirty years of cheating in high school. Adolescence 26(104):83947.

Shapiro, Samuel S. and Martin B. Wilk. 1965. An analysis of variance test for normality (complete samples). Biometrika 52(3/4):591-611.

Shariff, Azim F. and Ara Norenzayan. 2011. Mean gods make good people: Different views of God predict cheating behaviour. International Journal for the Psychology of Religion 21(2):85-96. 
Sheldon, Kennon M. and Andrew J. Elliot. 1999. Goal striving, need satisfaction, and longitudinal well-being: The self-concordance model. Journal of Personality and Social Psychology 76(3):482-97.

Silvia, Paul J. and Shelley T. Duval. 2001. Objective self-awareness theory: Recent progress and enduring problems. Personality and Social Psychology Review 5(3):230-41.

Stark, Rodney and William S. Baindbridge. 1996. Religion, deviance, and social control. New York: Routledge.

Steen, Johan, Tom Loeys, Beatrijs Moerkerke, and Stijn Vansteelandt. 2017. Medflex: An R package for flexible mediation analysis using natural effect models. Journal of Statistical Software 76(11):1-46.

Steensland, Brian, Jerry Z. Park, Mark D. Regnerus, W. Bradford Wilcox, and Robert D. Woodberry. 2000. The measure of American religion: Toward improving the state of the art. Social Forces 79(1):291-318.

Triandis, Harry C. 1989. The self and social behavior in differing cultural contexts. Psychological Review 96(3):506-20.

Uecker, Jeremy E. 2009. Catholic schooling, Protestant schooling, and religious commitment in young adulthood. Journal for the Scientific Study of Religion 48(2):353-67.

Ulmer, Jeffery T., Scott A. Desmond, Sung Joon Jang, and Byron R. Johnson. 2012. Religious involvement and dynamics of marijuana use: Initiation, persistence, and desistence. Deviant Behavior 33(6):448-68.

van Rompay, Thomas J. L., Dorette J. Vonk, and Marieke L. Fransen. 2009. The eye of the camera effects of security cameras on prosocial behavior. Environment and Behavior 41(1):60-74.

Weber, Max. [1930] 1992. The Protestant ethic and the spirit of capitalism. London: Routledge.

Wiltermuth, Scott S. 2011. Cheating more when the spoils are split. Organizational Behavior and Human Decision Processes 115(2):157-68.

Woodberry, Robert D. and Christian S. Smith. 1998. Fundamentalism et al: Conservative Protestants in America. Annual Review of Sociology 24(1):25-56.

Xie, Feng-Chang and Bo-Cheng Wei. 2007. Diagnostics analysis in censored generalized Poisson regression model. Journal of Statistical Computation and Simulation 77(8):695-708.

Yzerbyt, Vincent Y., Dominique Muller, and Charles M. Judd. 2004. Adjusting researchers' approach to adjustment: On the use of covariates when testing interactions. Journal of Experimental Social Psychology 40(3):424-31.

\section{SUPPORTING INFORMATION}

Additional Supporting Information may be found in the online version of this article at the publisher's website:

Appendix: Twenty Hints for Easy Words Used in Study 1 and Their Correct Answers 